\title{
A Note on "Common Fixed Point of Multistep Noor Iteration with Errors for a Finite Family of Generalized Asymptotically Quasi-Nonexpansive Mappings"
}

\author{
Satit Saejung, ${ }^{1,2}$ Suthep Suantai, ${ }^{2,3}$ and Pongsakorn Yotkaew ${ }^{1}$ \\ ${ }^{1}$ Department of Mathematics, Khon Kaen University, Khon Kaen 40002, Thailand \\ ${ }^{2}$ Centre of Excellence in Mathematics, CHE, Si Ayutthaya Road, Bangkok 10400, Thailand \\ ${ }^{3}$ Department of Mathematics, Chiang Mai University, Chiang Mai 50200, Thailand \\ Correspondence should be addressed to Satit Saejung, saejung@kku.ac.th \\ Received 20 October 2009; Accepted 11 December 2009 \\ Recommended by Simeon Reich \\ Copyright (c) 2009 Satit Saejung et al. This is an open access article distributed under the Creative \\ Commons Attribution License, which permits unrestricted use, distribution, and reproduction in \\ any medium, provided the original work is properly cited.
}

\section{Introduction}

Let $C$ be a nonempty subset of a Banach space $X$. A mapping $T: C \rightarrow C$ is said to be

(i) asymptotically nonexpansive [1] if there exists a sequence $\left\{k_{n}\right\}$ in $[0, \infty)$ such that $k_{n} \rightarrow 0$ and

$$
\left\|T^{n} x-T^{n} y\right\| \leq\left(1+k_{n}\right)\|x-y\|
$$

for all $x, y \in C$ and $n \geq 1$;

(ii) asymptotically quasi-nonexpansive [2] if $F(T)=\{p \in C: T p=p\} \neq \emptyset$ and there exists a sequence $\left\{k_{n}\right\}$ in $[0, \infty)$ such that $k_{n} \rightarrow 0$ and

$$
\left\|T^{n} x-p\right\| \leq\left(1+k_{n}\right)\|x-p\|
$$

for all $x \in C, p \in F(T)$ and $n \geq 1$; 
(iii) generalized asymptotically nonexpansive if there exist sequences $\left\{k_{n}\right\},\left\{l_{n}\right\}$ in $[0, \infty)$ such that $k_{n}, l_{n} \rightarrow 0$ and

$$
\left\|T^{n} x-T^{n} y\right\| \leq\left(1+k_{n}\right)\|x-y\|+l_{n}
$$

for all $x, y \in C$ and $n \geq 1 ;$

(iv) generalized asymptotically quasi-nonexpansive [3] if $F(T) \neq \emptyset$ and there exist sequences $\left\{k_{n}\right\},\left\{l_{n}\right\}$ in $[0, \infty)$ such that $k_{n}, l_{n} \rightarrow 0$ and

$$
\left\|T^{n} x-p\right\| \leq\left(1+k_{n}\right)\|x-p\|+l_{n}
$$

for all $x \in C, p \in F(T)$ and $n \geq 1$.

Many researchers have paid their attention on the approximation of a fixed point of a single mapping or a common fixed point of a family of mappings. One effective way is to use a sequence generated by an appropriate iteration. In this paper, we propose a general and short principle for proving some convergence results of certain types of iterative sequences. We also discuss and correct a small gap in the recent paper by Imnang and Suantai [4]. In the last section, we give a remark on the generalized asymptotically quasi-nonexpansive mapping in the sense of Lan [5].

Let $\left\{T_{i}\right\}_{i=1}^{N}$ be a finite family of self-mappings of a closed convex subset $C$ of $X$. The sequence $\left\{x_{n}\right\}$ is generated from $x_{1} \in C$, and

$$
\begin{aligned}
y_{1 n} & =\alpha_{1 n} T_{1}^{n} x_{n}+\beta_{1 n} x_{n}+\gamma_{1 n} u_{1 n} \\
y_{2 n} & =\alpha_{2 n} T_{2}^{n} y_{1 n}+\beta_{2 n} x_{n}+\gamma_{2 n} u_{2 n}, \\
& \vdots \\
y_{(N-1) n}= & \alpha_{(N-1) n} T_{N-1}^{n} y_{(N-2) n}+\beta_{(N-1) n} x_{n}+\gamma_{(N-1) n} u_{(N-1) n} \\
x_{n+1} & =\alpha_{N n} T_{N}^{n} y_{(N-1) n}+\beta_{N n} x_{n}+\gamma_{N n} u_{N n},
\end{aligned}
$$

where $\left\{u_{1 n}\right\},\left\{u_{2 n}\right\}, \ldots,\left\{u_{N n}\right\}$ are bounded sequences in $C$, and $\left\{\alpha_{i n}\right\},\left\{\beta_{i n}\right\}$, and $\left\{\gamma_{i n}\right\}$ are sequences in $[0,1]$ such that $\alpha_{i n}+\beta_{\text {in }}+\gamma_{\text {in }}=1$ for all $i=1,2, \ldots, N$ and $n \geq 1$.

\section{Main Results}

\subsection{Sequences of Monotone Types (1) and (2)}

Definition 2.1. Let $\left\{x_{n}\right\}$ be a sequence in a metric space $(X, d)$ and $F$ a subset of $X$. We say that $\left\{x_{n}\right\}$ is of

(i) monotone type (1) with respect to $F$ [6] if there exist sequences $\left\{r_{n}\right\}$ and $\left\{s_{n}\right\}$ of nonnegative real numbers such that $\sum_{n=1}^{\infty} r_{n}<\infty, \sum_{n=1}^{\infty} s_{n}<\infty$ and 
Abstract and Applied Analysis

$$
d\left(x_{n+1}, p\right) \leq\left(1+r_{n}\right) d\left(x_{n}, p\right)+s_{n}
$$

for all $n \geq 1$ and $p \in F$;

(ii) monotone type (2) with respect to $F$ if for each $p \in F$ there exist sequences $\left\{r_{n}\right\}$ and $\left\{s_{n}\right\}$ of nonnegative real numbers such that $\sum_{n=1}^{\infty} r_{n}<\infty, \sum_{n=1}^{\infty} s_{n}<\infty$ and

$$
d\left(x_{n+1}, p\right) \leq\left(1+r_{n}\right) d\left(x_{n}, p\right)+s_{n}
$$

for all $n \geq 1$.

Proposition 2.2. If $\left\{x_{n}\right\}$ is of monotone type (1) with respect to $F$, then it is of monotone type (2) with respect to $F$.

Lemma 2.3 ([7, Lemma 1]). Let $\left\{a_{n}\right\},\left\{b_{n}\right\}$, and $\left\{\alpha_{n}\right\}$ be sequences of nonnegative real numbers such that

$$
a_{n+1} \leq\left(1+\alpha_{n}\right) a_{n}+b_{n}, \quad n \geq 1 .
$$

If $\sum_{n=1}^{\infty} \alpha_{n}<\infty$ and $\sum_{n=1}^{\infty} b_{n}<\infty$, then $\lim _{n \rightarrow \infty} a_{n}$ exists.

Theorem 2.4. Let $(X, d)$ be a complete metric space, $F \subset X$, and $\left\{x_{n}\right\}$ a sequence in $X$. Then one has the following assertions.

(a) If $\left\{x_{n}\right\}$ is of monotone type (2) with respect to $F$, then $\lim _{n \rightarrow \infty} d\left(x_{n}, p\right)$ exists for all $p \in F$.

(b) If $\left\{x_{n}\right\}$ is of monotone type (1) with respect to $F$, then $\lim _{n \rightarrow \infty} d\left(x_{n}, F\right)$ exists.

(c) If $\left\{x_{n}\right\}$ is of monotone type (1) with respect to $F$ and $\liminf _{n \rightarrow \infty} d\left(x_{n}, F\right)=0$, then $x_{n} \rightarrow$ $p$ for some $p \in X$ satisfying $d(p, F)=0$. In particular, if $F$ is closed, then $p \in F$.

Proof. (a) It is easy to see that the result follows from (2.2) and Lemma 2.3.

(b) Note that $\left\{r_{n}\right\}$ and $\left\{s_{n}\right\}$ are independent of $p \in F$. Taking infimum over all $p \in F$ in (2.1) gives

$$
d\left(x_{n+1}, F\right) \leq\left(1+r_{n}\right) d\left(x_{n}, F\right)+s_{n} \quad \forall n \geq 1 .
$$

Again, by Lemma 2.3, we get that $\lim _{n \rightarrow \infty} d\left(x_{n}, F\right)$ exists. 
(c) It follows from (b) and $\lim \inf _{n \rightarrow \infty} d\left(x_{n}, F\right)=0$ that

$$
\lim _{n \rightarrow \infty} d\left(x_{n}, F\right)=0
$$

To show that $\left\{x_{n}\right\}$ is a Cauchy sequence, let $\varepsilon>0$. Since $\lim _{n \rightarrow \infty} d\left(x_{n}, F\right)=0$, we may assume without loss of generality that there is a sequence $\left\{p_{n}\right\}$ in $F$ such that $d\left(x_{n}, p_{n}\right) \leq \varepsilon / 4$ for all $n \geq 1$. As $\left\{x_{n}\right\}$ is bounded, we put $M=\sup \left\{d\left(x_{m}, p_{n}\right): m, n \geq 1\right\}$. From (2.1), we have

$$
d\left(x_{n+1}, p_{k}\right) \leq d\left(x_{n}, p_{k}\right)+t_{n} \quad \forall n, k \geq 1,
$$

where $t_{n} \equiv r_{n} M+s_{n}$. Consequently,

$$
d\left(x_{n+k}, p_{n}\right) \leq d\left(x_{n}, p_{n}\right)+\sum_{j=n}^{n+k-1} t_{j} \leq \frac{\varepsilon}{4}+\sum_{j=n}^{\infty} t_{j} \quad \forall n, k \geq 1
$$

Notice that $\sum_{n=1}^{\infty} t_{n}<\infty$. So there exists $N \geq 1$ such that $\sum_{n=N}^{\infty} t_{n}<\varepsilon / 2$. Then for all $n \geq N, k \geq$ 1 , we have

$$
d\left(x_{n+k}, x_{n}\right) \leq d\left(x_{n+k}, p_{n}\right)+d\left(x_{n}, p_{n}\right)<\varepsilon
$$

Hence, $\left\{x_{n}\right\}$ is a Cauchy sequence in $X$. By the completeness of $X$, we assume that $x_{n} \rightarrow p$ for some $p \in X$. Since

$$
\left|d\left(x_{n}, F\right)-d(p, F)\right| \leq d\left(x_{n}, p\right) \longrightarrow 0
$$

we obtain $d(p, F)=0$. This completes the proof.

\subsection{A Correction of Recent Results of Imnang and Suantai}

The following observation is an auxiliary result.

Proposition 2.5. Let $C$ be a nonempty subset of a Banach space $X$, and let $T_{1}, T_{2}, \ldots, T_{N}: C \rightarrow C$ be $N$ generalized asymptotically quasi-nonexpansive mappings with $F:=\bigcap_{i=1}^{N} F\left(T_{i}\right) \neq \emptyset$. Then there exist sequences $\left\{k_{n}\right\},\left\{l_{n}\right\}$ in $[0, \infty)$ such that $k_{n}, l_{n} \rightarrow 0$ and

$$
\left\|T_{i}^{n} x-p\right\| \leq\left(1+k_{n}\right)\|x-p\|+l_{n}
$$

for all $x \in C, p \in F, n \geq 1$, and $i=1,2, \ldots, N$.

From now on, we assume that $N$ generalized asymptotically quasi-nonexpansive mappings $T_{1}, T_{2}, \ldots, T_{N}: C \rightarrow C$ are equipped with the sequences $\left\{k_{n}\right\},\left\{l_{n}\right\}$ in $[0, \infty)$ as mentioned in the preceding proposition. 
Theorem 2.6. Let $C$ be a nonempty closed convex subset of a Banach space $X$, and $\left\{T_{1}, T_{2}, \ldots, T_{N}\right\}$ a finite family of generalized asymptotically quasi-nonexpansive self-mappings of $C$ with the sequence $\left\{\left(k_{n}, l_{n}\right)\right\}$ such that $\sum_{n=1}^{\infty} k_{n}<\infty$ and $\sum_{n=1}^{\infty} l_{n}<\infty$. Assume that $F:=\bigcap_{i=1}^{N} F\left(T_{i}\right) \neq \emptyset$ is closed, and $\left\{x_{n}\right\}$ is the sequence in $C$ defined by (1.5) such that $\sum_{n=1}^{\infty} \gamma_{i n}<\infty$ for each $i=1,2, \ldots, N$. Then the sequence $\left\{x_{n}\right\}$ converges strongly to a common fixed point of the family of mappings if and only if $\liminf _{n \rightarrow \infty} d\left(x_{n}, F\right)=0$.

Remark 2.7. There is a small gap in [4, Theorem 3.2]. More precisely, the sequence $\left\{x_{n}\right\}$ generated by (1.5) is shown in [4, Theorem 3.2] to be of monotone type (2) with respect to $F$, that is, $\left\|x_{n+1}-p\right\| \leq\left(1+k_{n}\right)^{N}\left\|x_{n}-p\right\|+e_{k n}$ where each $e_{k n}$ is a nonnegative real number depending on $p$. Then the expression $d\left(x_{n+1}, F\right) \leq\left(1+k_{n}\right)^{N} d\left(x_{n}, F\right)+e_{k n}$ cannot warrant.

Remark 2.8. The same gap also appears in [8, Lemma 2.3] and [6, Theorem 3.2].

Proof of Theorem 2.6. Necessity is obvious. Conversely, we show first that $\left\{x_{n}\right\}$ is of monotone type (2) with respect to $F$. Let $p \in F$. We have that

$$
\begin{aligned}
&\left\|y_{1 n}-p\right\|=\left\|\alpha_{1 n} T_{1}^{n} x_{n}+\beta_{1 n} x_{n}+\gamma_{1 n} u_{1 n}-p\right\| \\
& \leq \alpha_{1 n}\left\|T_{1}^{n} x_{n}-p\right\|+\beta_{1 n}\left\|x_{n}-p\right\|+\gamma_{1 n}\left\|u_{1 n}-p\right\| \\
& \leq\left(\alpha_{1 n}+\beta_{1 n}\right)\left(1+k_{n}\right)\left\|x_{n}-p\right\|+\alpha_{1 n} l_{n}+\gamma_{1 n}\left\|u_{1 n}-p\right\| \\
& \leq\left(1+k_{n}\right)\left\|x_{n}-p\right\|+\tilde{l}_{1 n}
\end{aligned}
$$

where $\tilde{l}_{1 n} \equiv \alpha_{1 n} l_{n}+\gamma_{1 n}\left\|u_{1 n}-p\right\|$. Notice that $\sum_{n=1}^{\infty} l_{n}<\infty$ and $\left\{u_{1 n}\right\}$ is bounded. Then $\sum_{n=1}^{\infty} \tilde{l}_{1 n}<$ $\infty$. It follows from (2.12) that

$$
\begin{aligned}
\left\|y_{2 n}-p\right\| & \leq \alpha_{2 n}\left\|T_{2}^{n} y_{1 n}-p\right\|+\beta_{2 n}\left\|x_{n}-p\right\|+\gamma_{2 n}\left\|u_{2 n}-p\right\| \\
& \leq \alpha_{2 n}\left(1+k_{n}\right)\left\|y_{1 n}-p\right\|+\alpha_{2 n} l_{n}+\beta_{2 n}\left\|x_{n}-p\right\|+\gamma_{2 n}\left\|u_{2 n}-p\right\| \\
& \leq\left(\alpha_{2 n}+\beta_{2 n}\right)\left(1+k_{n}\right)^{2}\left\|x_{n}-p\right\|+\alpha_{2 n}\left(\left(1+k_{n}\right) \tilde{l}_{1 n}+l_{n}\right)+\gamma_{2 n}\left\|u_{2 n}-p\right\| \\
& \leq\left(1+k_{n}\right)^{2}\left\|x_{n}-p\right\|+\tilde{l}_{2 n},
\end{aligned}
$$

where $\tilde{l}_{2 n} \equiv \alpha_{2 n}\left(\left(1+k_{n}\right) \tilde{l}_{1 n}+l_{n}\right)+\gamma_{2 n}\left\|u_{2 n}-p\right\|$. Notice that $\sum_{n=1}^{\infty} k_{n}<\infty, \sum_{n=1}^{\infty} l_{n}<\infty, \sum_{n=1}^{\infty} \tilde{l}_{1 n}<\infty$ and $\left\{u_{2 n}\right\}$ is bounded. Then $\sum_{n=1}^{\infty} \tilde{l}_{2 n}<\infty$. By continuing this process, there is a sequence $\left\{\tilde{l}_{k n}\right\}$ of nonnegative real numbers such that $\sum_{n=1}^{\infty} \tilde{l}_{k n}<\infty$ and

$$
\left\|x_{n+1}-p\right\| \leq\left(1+k_{n}\right)^{N}\left\|x_{n}-p\right\|+\tilde{l}_{k n}
$$


Then $\left\{x_{n}\right\}$ is of monotone type (2) with respect to $F$. By Theorem 2.4(a), we get that $\lim _{n \rightarrow \infty}\left\|x_{n}-p\right\|$ exists and $\left\{x_{n}\right\}$ is bounded. Next, we show that $\left\{x_{n}\right\}$ is of monotone type (1) with respect to $F$. It follows from (2.11) that

$$
\begin{aligned}
\left\|y_{1 n}-p\right\| & \leq\left(\alpha_{1 n}+\beta_{1 n}\right)\left(1+k_{n}\right)\left\|x_{n}-p\right\|+\alpha_{1 n} l_{n}+\gamma_{1 n}\left\|u_{1 n}-p\right\| \\
& \leq\left(\alpha_{1 n}+\beta_{1 n}\right)\left(1+k_{n}\right)\left\|x_{n}-p\right\|+\alpha_{1 n} l_{n}+\gamma_{1 n}\left(\left\|x_{n}-p\right\|+\left\|x_{n}-u_{1 n}\right\|\right) \\
& \leq\left(1+k_{n}\right)\left\|x_{n}-p\right\|+\tilde{l}_{1 n}
\end{aligned}
$$

where $\tilde{l}_{1 n} \equiv \alpha_{1 n} l_{n}+\gamma_{1 n}\left\|x_{n}-u_{1 n}\right\|$. Notice that $\left\{u_{1 n}\right\},\left\{x_{n}\right\}$ are bounded and $\sum_{n=1}^{\infty} l_{n}<\infty$. Then $\sum_{n=1}^{\infty} \tilde{l}_{1 n}<\infty$ and $\left\{\tilde{l}_{1 n}\right\}$ is independent of $p$. Again, by continuing this process, we obtain a sequence $\left\{\tilde{l}_{k n}\right\}$ of nonnegative real numbers such that it is independent of $p, \sum_{n=1}^{\infty} \tilde{l}_{k n}<\infty$ and

$$
\left\|x_{n+1}-p\right\| \leq\left(1+k_{n}\right)^{N}\left\|x_{n}-p\right\|+\tilde{l}_{k n}
$$

for all $n \geq 1$ and $p \in F$. Then $\left\{x_{n}\right\}$ is of monotone type (1) with respect to $F$. Hence the result follows from (2.16) and Theorem 2.4(c). This completes the proof.

Remark 2.9. Theorem 2.4 is a correction of [4, Theorem 3.2]. In fact, the closedness of $F$ is not assumed there (this defect is now corrected after the submission of this article). Moreover, it is shown in the following example that the fixed point set of a generalized asymptotically nonexpansive mapping is not necessarily closed even in a Hilbert space.

Example 2.10 (A generalized asymptotically nonexpansive mapping whose fixed point set is not closed). Let $T:[-1 / 2,1 / 2] \rightarrow[-1 / 2,1 / 2]$ be a mapping defined by

$$
T x= \begin{cases}x, & \text { if } x \in\left[-\frac{1}{2}, 0\right), \\ \frac{1}{4}, & \text { if } x=0 \\ x^{2}, & \text { if } x \in\left(0, \frac{1}{2}\right] .\end{cases}
$$

Then $T$ is generalized asymptotically nonexpansive.

Proof. Notice that $F(T)=[-1 / 2,0)$ is not closed. We prove that

$$
\left|T^{n} x-T^{n} y\right| \leq|x-y|+\frac{1}{2^{2^{n}}}
$$

for all $x, y \in[-1 / 2,1 / 2]$ and $n \geq 1$. The inequality above holds trivially if $x=y=0$ or $x, y \in[-1 / 2,0)$. Then it suffices to consider the following cases. 
Case $1(x, y \in(0,1 / 2])$. Then

$$
\left|T^{n} x-T^{n} y\right|=\left|x^{2^{n}}-y^{2^{n}}\right| \leq \frac{1}{2^{2^{n}}} .
$$

Case $2(x \in[-1 / 2,0)$ and $y=0)$. Then

$$
\left|T^{n} x-T^{n} y\right|=\left|x-\frac{1}{2^{2^{n}}}\right| \leq|x-y|+\frac{1}{2^{2^{n}}} .
$$

Case $3(x \in[-1 / 2,0)$ and $y \in(0,1 / 2])$. Then

$$
\left|T^{n} x-T^{n} y\right|=\left|x-y^{2^{n}}\right| \leq|x-y| .
$$

Case $4(x=0$ and $y \in(0,1 / 2])$. Then

$$
\left|T^{n} x-T^{n} y\right|=\left|\frac{1}{2^{2^{n}}}-y^{2^{n}}\right| \leq|x-y|+\frac{1}{2^{2^{n}}} .
$$

Hence, (2.18) holds. This completes the proof.

Remark 2.11. For $T$ which is defined in Example 2.10 and $x_{1} \in(0,1 / 2]$, we define

$$
x_{n+1}=\alpha_{n} T^{n} x_{n}+\left(1-\alpha_{n}\right) x_{n}
$$

where $0<a \leq \alpha_{n} \leq 1$ and $n \geq 1$. It is not hard to show that $x_{n} \rightarrow 0 \notin F(T)$ and $d\left(x_{n}, F(T)\right) \rightarrow$ 0 . Hence [4, Theorems 3.2 and 3.6] do not hold even for a single mapping if the closedness of the fixed point set is not assumed.

We present a sufficient condition guaranteeing the closedness of the fixed point set of a generalized asymptotically quasi-nonexpansive mapping.

Theorem 2.12. Let $C$ be a nonempty subset of a Banach space $X$ and $T: C \rightarrow C$ a generalized asymptotically quasi-nonexpansive mapping. If $G(T):=\{(x, T x): x \in C\}$ is closed, then $F(T)$ is closed.

Proof. Let $\left\{p_{n}\right\}$ be a sequence in $F(T)$ such that $p_{n} \rightarrow p$. Since $T$ is a generalized asymptotically quasi-nonexpansive mapping with the sequence $\left\{\left(k_{n}, l_{n}\right)\right\}$, we have

$$
\begin{aligned}
\left\|T^{n} p-p\right\| & \leq\left\|T^{n} p-p_{n}\right\|+\left\|p_{n}-p\right\| \\
& \leq\left(1+k_{n}\right)\left\|p-p_{n}\right\|+l_{n}+\left\|p_{n}-p\right\| \longrightarrow 0
\end{aligned}
$$

Then $T^{n} p \rightarrow p$, and so $T\left(T^{n} p\right)=T^{n+1} p \rightarrow p$. Hence, by the closedness of $G(T), T p=p$. This completes the proof. 
Remark 2.13. It is also worth mentioning that the $(L-\gamma)$ uniform Lipschitz condition of mappings in [4, Theorems 4.2 and 4.3] implies the closedness of their graphs.

The following result shows that the closedness of $G(T)$ can be dropped if $T$ is asymptotically quasi-nonexpansive.

Theorem 2.14. Let $C$ be a nonempty subset of a Banach space $X$, and $T: C \rightarrow C$ an asymptotically quasi-nonexpansive mapping. Then $F(T)$ is closed.

Proof. Suppose that $T$ is an asymptotically quasi-nonexpansive mapping with the sequence $\left\{k_{n}\right\}$. Let $\left\{p_{n}\right\}$ be a sequence in $F(T)$ such that $p_{n} \rightarrow p$. We have

$$
\begin{aligned}
\|T p-p\| & \leq\left\|T p-p_{n}\right\|+\left\|p_{n}-p\right\| \\
& \leq\left(1+k_{1}\right)\left\|p-p_{n}\right\|+\left\|p_{n}-p\right\| \longrightarrow 0 .
\end{aligned}
$$

Then $T p=p$. This completes the proof.

Remark 2.15. Not every generalized asymptotically quasi-nonexpansive mapping is asymptotically quasi-nonexpansive. In fact, the mapping $T$ in Example 2.10 is not asymptotically quasi-nonexpansive since $F(T)$ is not closed.

\section{Remark on Lan's Generalized Asymptotically Quasi-Nonexpansive Mappings}

The following mapping introduced by Lan [5] also bears the name generalized asymptotically quasi-nonexpansive mappings. We recall his definition here.

Definition 3.1 (see [5, Definition 2.1(4)]). Let $C$ be a subset of a Banach space X. A mapping $T: C \rightarrow C$ is called generalized asymptotically quasi-nonexpansive in the sense of Lan if there exists two sequences $\left\{r_{n}\right\} \subset[0, \infty)$ and $\left\{s_{n}\right\} \subset[0,1)$ such that $r_{n}, s_{n} \rightarrow 0$ and

$$
\left\|T^{n} x-p\right\| \leq\left(1+r_{n}\right)\|x-p\|+s_{n}\left\|x-T^{n} x\right\|
$$

for all $x \in C, p \in F(T)$, and $n \geq 1$.

Lan [5] and many authors (e.g., [8-11]) have investigated convergence theorems for such mappings without awareness that Lan's mappings are not new ones.

Proposition 3.2. If $T: C \rightarrow C$ is generalized asymptotically quasi-nonexpansive in the sense of Lan, then it is asymptotically quasi-nonexpansive.

Proof. By Lan's definition, there exist two sequences $\left\{r_{n}\right\} \subset[0, \infty)$ and $\left\{s_{n}\right\} \subset[0,1)$ such that $r_{n}, s_{n} \rightarrow 0$ and

$$
\left\|T^{n} x-p\right\| \leq\left(1+r_{n}\right)\|x-p\|+s_{n}\left\|x-T^{n} x\right\|
$$


for all $x \in C, p \in F(T)$, and $n \in \mathbb{N}$. Consequently,

$$
\left\|T^{n} x-p\right\| \leq\left(1+r_{n}\right)\|x-p\|+s_{n}\left(\|x-p\|+\left\|T^{n} x-p\right\|\right) .
$$

This implies

$$
\left\|T^{n} x-p\right\| \leq \frac{1+r_{n}+s_{n}}{1-s_{n}}\|x-p\|=\left(1+\frac{r_{n}+2 s_{n}}{1-s_{n}}\right)\|x-p\|
$$

It is also clear that $\left(r_{n}+2 s_{n}\right) /\left(1-s_{n}\right) \rightarrow 0$ and this completes the proof.

\section{Acknowledgments}

The research of the first and second authors is partially supported by the Centre of Excellence in Mathematics, the Commission on Higher Education of Thailand. The third author was supported by the Human Resource Development in Science Project.

\section{References}

[1] K. Goebel and W. A. Kirk, "A fixed point theorem for asymptotically nonexpansive mappings," Proceedings of the American Mathematical Society, vol. 35, pp. 171-174, 1972.

[2] Q. Liu, "Iterative sequences for asymptotically quasi-nonexpansive mappings with error member," Journal of Mathematical Analysis and Applications, vol. 259, no. 1, pp. 18-24, 2001.

[3] N. Shahzad and H. Zegeye, "Strong convergence of an implicit iteration process for a finite family of generalized asymptotically quasi-nonexpansive maps," Applied Mathematics and Computation, vol. 189, no. 2, pp. 1058-1065, 2007.

[4] S. Imnang and S. Suantai, "Common fixed points of multistep Noor iterations with errors for a finite family of generalized asymptotically quasi-nonexpansive mappings," Abstract and Applied Analysis, vol. 2009, Article ID 728510, 14 pages, 2009.

[5] H.-Y. Lan, "Common fixed-point iterative processes with errors for generalized asymptotically quasinonexpansive mappings," Computers $\mathcal{E}$ Mathematics with Applications, vol. 52, no. 10-11, pp. 1403-1412, 2006.

[6] H. Y. Zhou, G. L. Gao, G. T. Guo, and Y. J. Cho, "Some general convergence principles with applications," Bulletin of the Korean Mathematical Society, vol. 40, no. 3, pp. 351-363, 2003.

[7] K.-K. Tan and H. K. Xu, "Approximating fixed points of nonexpansive mappings by the Ishikawa iteration process," Journal of Mathematical Analysis and Applications, vol. 178, no. 2, pp. 301-308, 1993.

[8] Y. J. Cho, J. K. Kim, and H. Y. Lan, "Three step iterative procedure with errors for generalized asymptotically quasi-nonexpansive mappings in Banach spaces," Taiwanese Journal of Mathematics, vol. 12, no. 8, pp. 2155-2178, 2008.

[9] W. Cholamjiak and S. Suantai, "Approximating common fixed point of a finite family of generalized asymptotically quasi-nonexpansive mappings," Thai Journal of Mathematics, vol. 6, no. 2, pp. 315-322, 2008.

[10] J. Nantadilok, "Common fixed-point $N$-step iteration schemes with errors for finite family of generalized asymptotically quasi-nonexpansive mappings," JP Journal of Fixed Point Theory and Applications, vol. 3, no. 3, pp. 199-218, 2008.

[11] J. Nantadilok, "Three-step iteration schemes with errors for generalized asymptotically quasinonexpansive mappings," Thai Journal of Mathematics, vol. 6, no. 2, pp. 295-306, 2008. 


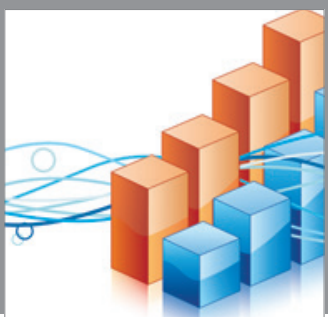

Advances in

Operations Research

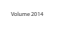

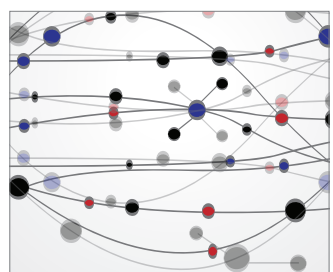

\section{The Scientific} World Journal
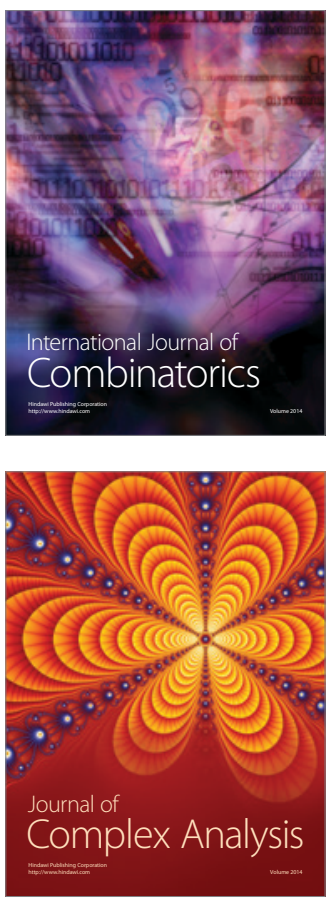

International Journal of

Mathematics and

Mathematical

Sciences
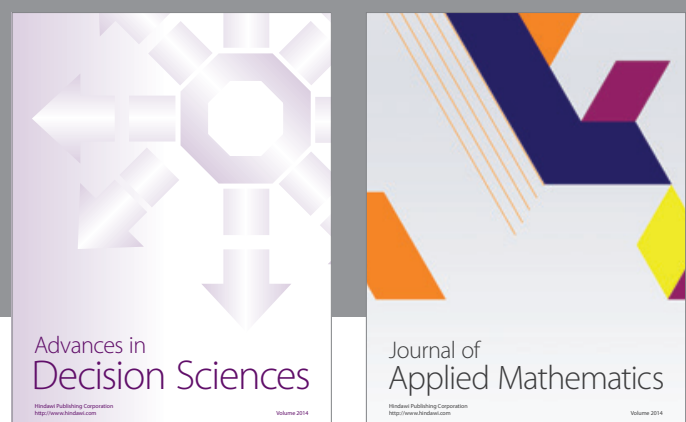

Journal of

Applied Mathematics
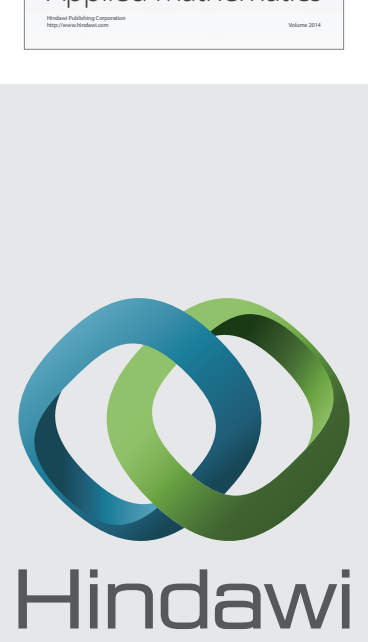

Submit your manuscripts at http://www.hindawi.com
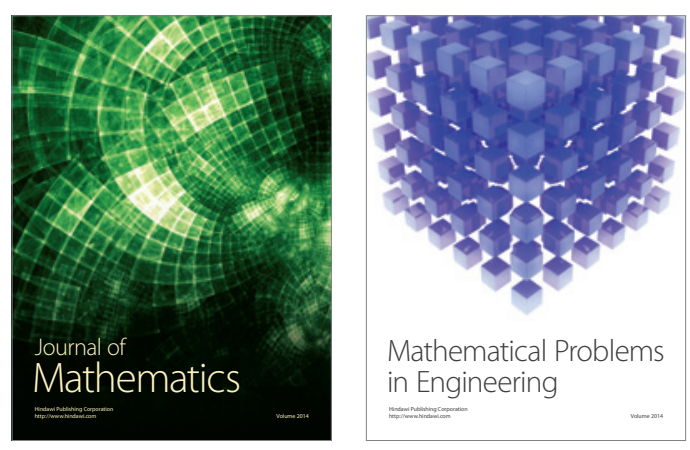

Mathematical Problems in Engineering
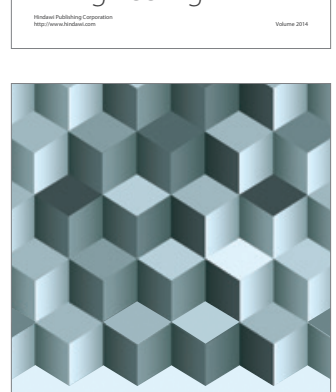

Journal of

Function Spaces
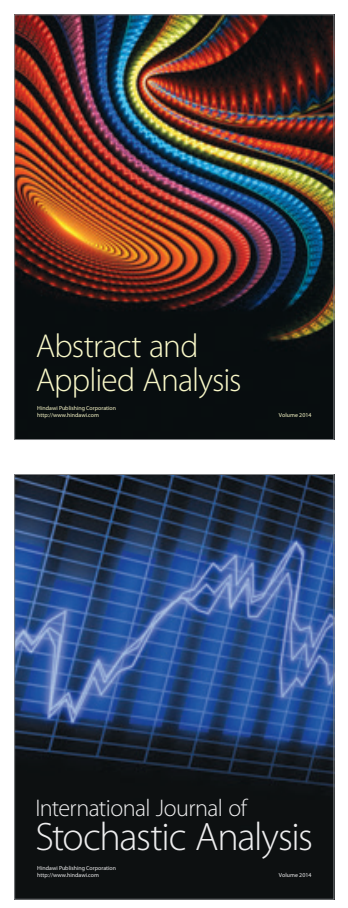

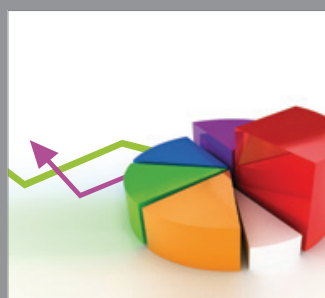

ournal of

Probability and Statistics

Promensencen
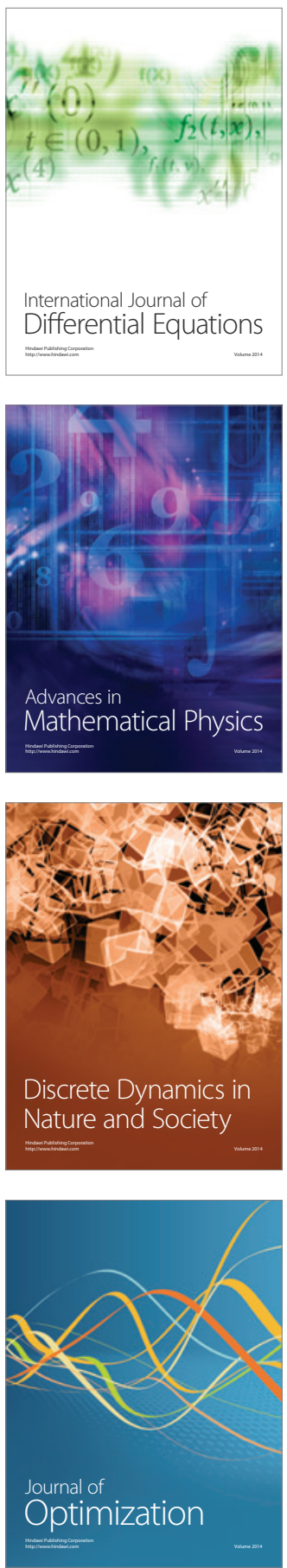